\title{
Responsabilidade social das empresas nas práticas das organizações da sociedade civil em cidades do norte do Rio Grande do Sul
}

\author{
Corporate social responsibility for the practice of civil society organizations in \\ cities in the north of Rio Grande do Sul
}

\author{
Jaqueline Santos ${ }^{1}$ \\ Eliana Andréa Severo ${ }^{2}$
}

\begin{abstract}
Resumo
A responsabilidade social empresarial (RSE) é um conjunto de políticas e ações que as empresas adotam voluntariamente para contribuir com a sociedade, e essas ações podem ocorrer por meio das organizações da sociedade civil (OSC), as quais fazem parte do chamado terceiro setor. O objetivo deste estudo consiste em analisar a contribuição das ações da RSE para as práticas das OSC situadas nas quatro maiores cidades da região norte do Rio Grande do Sul. Trata-se de uma pesquisa qualitativa, exploratória e sob a abordagem de estudo de casos múltiplos, aplicados a 14 organizações da sociedade civil e 11 empresas do setor privado que contribuem com essas OSC. Os principais resultados destacam que o terceiro setor e as empresas entendem que desempenham atividades que seriam do Estado, as quais contribuem significativamente para o desenvolvimento regional. Os recursos e outras ajudas oferecidos pelas empresas às OSC são significativos, principalmente, para despesas não previstas, que surgem na rotina das OSC participantes da pesquisa e para oferecer algo a mais aos beneficiados. As contribuições entre empresas e OSC são vistas, tanto pelas OSC quanto pelas empresas, como uma contrapartida, na qual as empresas fornecem insumos e as OSC oferecem serviços sociais.
\end{abstract}

Palavras-chave: Responsabilidade social empresarial; Organizações da sociedade civil; Terceiro setor.

\begin{abstract}
Corporate social responsibility (CSR) is a set of policies and actions that companies adopt voluntarily to contribute to society, and these actions can occur through civil society organizations (CSO), which are part of the so called third sector. The aim of this study is to analyze the contribution of the actions of CSR to the practices of CSO located in the four largest cities in the northern region of Rio Grande do Sul. It is a qualitative and exploratory research which uses the approach of multiple cases applied to 14 civil society organizations and 11 private sector companies that contribute to these CSO. The main results highlight that the third sector and companies understand that they perform activities that would be the duty of the state, which contribute significantly to the regional development. Resources and other assistance offered by companies to CSO are especially significant for unforeseen expenses that arise in the routine of the participating CSO and to offer something else for to the benefited people, and the contributions between companies and CSO are seen both by CSO and by the companies, as a contrast, in which companies provide input and CSO provide social services.
\end{abstract}

Keywords: Corporate Social Responsibility; Civil Society Organizations; Third sector.

\section{Introdução}

A responsabilidade social empresarial (RSE)é um conjunto de políticas e ações que as empresas adotam voluntariamente para contribuir com a sociedade e o desenvolvimento regional. Seja por meio de recursos tangíveis, como dinheiro, terrenos, instalações, máquinas, suprimentos, estruturas e recursos naturais, seja por meio de recursos intangíveis, como conhecimentos, capacidades, práticas de gestão e habilidades (AUSTIN; SEITANIDI, 2012; OMETTO; BULGACOV; MAY, 2015).

Mestrado em Administração pela Faculdade Meridional (IMED). Brasil. Afiliação: Faculdade Meridional (IMED). Email: jaque_s2004@yahoo. com.br

2 Doutora em Administração pela Pontifícia Universidade Católica do Rio Grande do Sul (PUCRS). Brasil. Afiliação: Universidade Potiguar (UNP). Lattes: http://lattes.cnpq.br/0272640518459010 ORCID: http://orcid.org/0000-0002-5970-4032 Email: elianasevero2@hotmail.com 
Destaca-se um aumento no interesse das empresas brasileiras por RSE, especialmente a partir da década de 90, quando passaram a dar mais atenção aos aspectos sociais de sua atuação na busca por mudanças e melhorias. A RSE torna-se um fenômeno generalizado no mundo corporativo, bem como tema em destaque nos estudos sobre gestão, levando as empresas a refletirem sobre as questões sociais e as consequências do seu sucesso (LIN-HI; HÖRISCH; BLUMBERG, 2015; LENZIARDI, 2017; MATTEN; MOON, 2008). Entretanto, cabe também às políticas públicas realizar a concepção, planejamento e implementação de programas públicos que atendam às necessidades sociais.

Conforme Yadlapalli, Rahman e Gunasekaran (2018), na última década, as preocupações políticas e sociais motivaram ações que envolvem a RSE. Nesse contexto, as organizações da sociedade civil (OSC) fazem parte do terceiro setor e atendem demandas sociais que o setor público não consegue abranger, desempenhando funções que competem ao Estado.De acordo com Cuadra (2014), muitos governos reconhecem a importância da participação cidadã nas políticas públicas sociais, mas, em alguns casos, ela é pouco estimulada. No Brasil, entretanto, o governo vem desenvolvendo políticas direcionadas para a RSE no âmbito das pessoas e OSC.Dentre essas políticas estão os programas sociais para a população que têm compromisso de assegurar direitos sociais nas áreas de saúde, educação e assistência social. Consoante isso, as políticas públicas sociais e o posicionamento do governo pode influenciar o acesso aos bens públicos e impactar na atenção às necessidades das populações carentes.

De acordo com a UNESCO (2010) e o Ministério do Desenvolvimento Social (2017), em âmbito governamental, o Programa Bolsa Família cumpre um papel importante na ampliação do orçamento familiar dos mais pobres, pois beneficia famílias em situação de pobreza.Segundo Novaes (2010), é possível apontar indícios de pequeno impacto nas condições de vida de uma camada da população brasileira marcada pela exclusão e pelo abandono de políticas públicas que privilegiaram setores e regiões do país, em detrimento de outros mais carentes, embora ainda seja necessário resultado sustentável a ponto de mudar o quadro social vigente no país.

No âmbito social, as OSC encontram diversas dificuldades na prestação de serviços, sejam financeiras,sejam de gestão, e essas dificuldades podem ser amenizadas com a colaboração das empresas e governo, financeira ou de outras formas buscando trabalhar seu lado social, mais especificamente atendendo aos critérios de ser para prestar ajuda social e obter outros benefícios que partem dela. Diante dessas dificuldades, muitas OSC criam colaborações ou parcerias com outros setores para resolver problemas sociais, em que as empresas podem buscar o fortalecimento e comprometimento dos colaboradores que atuam nas atividades de RSE, assim como um envolvimento mais amplo coma comunidade,para, além de tratar de questões sociais ou ambientais, produzir benefícios organizacionais para ambas, por exemplo: as empresas fornecendo recursos e as OSC oferecendo serviços sociais. Para as OSC, essas parcerias podem aumentar a sua capacidade e ajudar a atingir seus objetivos de forma mais eficaz (CHO; KELLY, 2014; SALAMON, 1998; AUSTIN, 2000; SUÁREZ; HWANG, 2013).

Perante o exposto, a proposta da presente pesquisa é responder a seguinte questão: como as ações de responsabilidade social contribuem para as práticas das OSC? Consoante isso, o estudo foi aplicado em 11 empresas e 14 OSC, privadas e sem fins lucrativos, das quatro maiores cidades da região norte do Rio Grande do Sul (RS), que têm ligação por meio das ações de responsabilidade social desenvolvidas pelas empresas.Para tanto, o objetivo do estudo consiste em analisar a contribuição das ações de responsabilidade social das empresas para as práticas das organizações da sociedade civil, bem como verificar as contribuições das ações das organizações da sociedade civil para a sociedade e o desenvolvimento regional.

A pesquisa justifica-se pelo fato de os problemas sociais que atingem as comunidades necessitarem de apoio de diversos setores da economia, para amenizá-los ou solucioná-los, o que contribui para o desenvolvimento regional. E as OSC têm uma participação especial nesse trabalho, pois atuam em situações nas quais essas comunidades não são atendidas. Entretanto as OSC contam com certo apoio dos demais setores, o que torna relevante entender as contribuições advindas das práticas de RSE, pois, segundo Salamon (2010), as OSC têm uma combinação única de estrutura privada e finalidade pública, têm conexões com os cidadãos, flexibilidade e capacidade em envolver a iniciativa privada em apoio afins públicos. 


\section{Referencial teórico}

\subsection{Responsabilidade social empresarial}

As definições de RSE geralmente referem-se a servir a sociedade em questões além do que é legalmente exigido, abrangendo uma variedade de práticas organizacionais que se destinam a servir as partes interessadas, além dos proprietários da empresa, incluindo colaboradores, fornecedores, clientes, comunidade e sociedade em geral (CARROLL, 1998; CARROLL; SHABANA, 2010; CHIN; HAMBRICH; TREVIÑO, 2013; JO; HARJOTO, 2011;YADLAPALLI; RAHMAN; GUNASEKARAN, 2018). Contudo, embora existam estudos sobre o contexto institucional e social em relação à RSE, ainda existem lacunas importantes nesse entendimento (CORRIGAN, 2018). Conforme Wang e Sarkis (2017), as empresas implementam a governança de RSE com sucesso para gerar bons resultados de responsabilidade social, o que desempenha um papel importante, influenciando o desempenho financeiro das empresas.

No âmbito governamental, as políticas públicas, em relação à promoção do desenvolvimento econômico local por meio de incentivos fiscais e outros incentivos empresariais,são relevantes para o desenvolvimento regional (BARTIK; EBERTS, 2012). De acordo com Borges (2014), a política de incentivos fiscais tem sido um instrumento eficaz para a aceleração do desenvolvimento estadual e a promoção de mudanças no perfil de seu sistema produtivo.

Nesse contexto, observou-se um aumento no interesse das empresas brasileiras por responsabilidade social na mesma época em que foram criados o Grupo de Institutos e Fundações Empresariais (GIFE) e o Instituto Ethos de Empresas e Responsabilidade Social, os quais têm o objetivo de difundir práticas de RSE e baseiam-se na premissa de que apenas o Estado não conseguiria cuidar do bem-estar da sociedade, por isso as empresas e suas organizações privadas e sem fins lucrativos teriam um papel essencial em preencher essa lacuna (SAUERBRONN; SAUERBRONN, 2011). Dessa forma, as empresas mudaram sua visão e forma de intervir nos aspectos sociais, passando a assumir um papel de agente de mudança social (MATHIS; MATHIS, 2012), assim como na aquisição de legitimidade local nas comunidades vizinhas (RODRIGUES; MENDES, 2018).

Nesse cenário, as organizações também se preocupam com a imagem social, pois, conforme Mendonça e Gonçalves (2004) e Seramim, Zanella e Rojo (2017),empresas que assumem uma dimensão socialmente responsável melhoram a sua imagem interna e ganham o respeito das comunidades com as quais interagem.

A participação das empresas em iniciativas de RSE pode desencadear uma verdadeira mudança social e também têm o potencial de mudar a cultura corporativa. Essas iniciativas incluem ações dentro da empresa, envolvendo ser socialmente responsável para com os funcionários, bem como as ações fora dela,como a realização de investimentos em infraestrutura de comunidades locais ou desenvolvimento de iniciativas comunitárias filantrópicas(AGUILERA et al., 2007).

Segundo Agarwal (2014), existem dois tipos de RSE:i) empresas que fornecem financiamento e recursos para causas de valor social, como a doação de dinheiro ou tempo de funcionários para essas causas; e ii) produção de produtos ou prestação de serviços alinhados aos melhores interesses da sociedade. De forma que, essas práticas sociais das empresas não se limitam apenas às doações monetárias das próprias empresas, mas também muitas incentivam atividades filantrópicas por seus funcionários, clientes e demais stakeholderspor meio de várias formas de colaboração (CARROLL; SHABANA, 2010).

Nesse sentido, os colaboradores podem ajudar inclusive nos processos de decisão referentes aos assuntos da empresa, incluindo questões de RSE nas quais a empresa esteja engajada, podendo afetar positivamente as atitudes e comportamentos dos colaboradores (AGUILERA et al., 2007; REGO et al., 2010; OHANA; MEYER; SWATON, 2012). Por outro lado, Wong, Ormiston e Tetlock (2011) apontam que, quando o processo de tomada de decisão é centralizado, pode reduzir o desejo dos colaboradores de se envolverem em questões de desempenho social da empresa.

A contribuição das empresas para fins sociais permite o ganho de legitimidade sociopolítica, obtenção de respostas positivas dos stakeholders e acesso político, sendo que a legitimidade social ou aprovação do público pode auxiliar as empresas na cooperação e apoio dos stakeholders, permitindo o acesso a recursos políticos fundamentais para seu desenvolvimento (WANG; QIAN, 2011).O engajamento em responsabilidade 
social é importante para a construção de confiança e capital social (JO; HARJOTO, 2011),pois quando a RSE promove a comunicação aberta com os stakeholders e a transparência, isso aumenta a confiança da sociedade na empresa,= e, por consequência, o capital social (BOULOUTA; PITELIS, 2014). Além disso, essas ações podem ter um efeito positivo sobre o valor de mercado de uma empresa, o que poderá beneficiar a todos os envolvidos (JO; HARJOTO, 2011; MACKEY; MACKEY; BARNEY, 2007).

Uma forma importante de incentivo para a participação das empresas em responsabilidade social são as necessidades das OSC por colaborações, o que pode levar as empresas a se envolverem em RSE, O que contribui para ambas as organizações (AGUILERA et al., 2007).

\subsection{Colaborações entre empresas e organizações da sociedade civil}

Muitas OSC criam colaborações ou parcerias com outros setores para resolver problemas sociais complexos, e muitas empresas, para cumprir a sua responsabilidade social e ter um maior envolvimento com suas comunidades, implementam atividades filantrópicas, como doação de dinheiro e de recursos não monetários para organizações sem fins lucrativos, sendo essas colaborações intersetoriais um fenômeno importante e em expansão (AUSTIN, 2000; CHO; KELLY, 2014).

Há convergência de pressões políticas, econômicas e sociais pode promover a colaboração entre empresas, OSC e governo. Contudo, os governos são limitados, no que se refere à prestação de serviços sociais e comunitários. Essas funções são, em muitos casos, exercidas pelo terceiro setor e setor privado, OSC e empresas. A partir disso, as OSC buscam identificar causas e propor soluções para esses problemas, capacitando os cidadãos para participar de ações coletivas(AUSTIN, 2000; SALAMON, 1998, MINZNER et al., 2014).

No que se refere a recursos públicos para as OSC, Verschuere e De Corte (2014), salientam que a dependência desses recursos parece ter um impacto negativo sobre a autonomia para a tomada de decisões das OSC, como a definição da sua missão, os procedimentos de trabalho, os resultados a serem alcançados e os grupos alvos a serem atingidos.

Nesse contexto, outras limitações das OSC, como falha nas competências, práticas e sistemas, que impedem seu crescimento, sustentabilidade e eficácia, têm levado financiadores a investir nas OSC por meio de assistência, treinamento e fundos de subsídios técnicos para melhorar os resultados para os beneficiados dessas organizações (MINZNER et al., 2014).

As OSC podem evitar comportamento irresponsável como peculato, fraude de voluntários, irregularidades nas receitas, práticas questionáveis de angariação de fundos e danos ambientais por meio do treinamento e educação dos seus membros. Então, a fim de voluntariar comportamentos que promovam um funcionamento eficiente e eficaz, são essenciais atitudes e estruturas regulamentadas por parte das OSC (LIN-HI; HÖRISCH; BLUMBERG, 2015; SCHIE et al., 2015).

As situações de crise econômica podem levar a uma maior procura pelos serviços das OSC, criando uma pressão sobre os recursos disponíveis, diminuindo suas fontes de renda ou mesmo os recursos disponíveis para doações (SUÁREZ; HWANG, 2013). Coerentemente, as empresas podem atingir dois objetivos simultaneamente: contribuir para a solução de problemas da sociedade, criando valor social, e entregar ganhos econômicos, criando valor financeiro; podendo ser uma função de demandas institucionais para a adequação ou a disposição de recursos (AL-TABBAA; LEACH; MARCH, 2014; AUSTIN; SEITANIDI, 2012; CHO; KELLY, 2014).

Conforme Suárez e Hwang (2013), muitas OSC buscam a melhoria dos serviços que oferecem, solicitando uma variedade de doações e outras formas de assistência das empresas e desenvolvendo laços que podem depender do compartilhamento de uma causa, dos interesses em comum e também das

suas necessidades de recursos e desafios financeiros. Tendo em vista que as empresas estão procurando envolver-se mais na busca de soluções para problemas sociais, isso pode ser uma oportunidade para que as OSC busquem essas colaborações (CHO; KELLY, 2014; HARRIS, 2012; SUÁREZ; HWANG, 2013).

A fim de avaliar a complementariedade dos recursos e seu potencial de criação de valor é importante reconhecer a natureza dos recursos que cada parceiro tem o potencial de oferecer, incluindo recursos tangíveis 
e intangíveis, não se exigindo apenas que os parceiros tenham interesses em comum, mas também para incorporar as percepções de valor nas comunidades locais dos beneficiários e demais partes interessadas (AUSTIN; SEITANIDI, 2012).

De acordo com Suárez e Hwang (2013) e Al-Tabbaa, Leach e March (2014), sugere-se que as OSC procurem diversificar suas fontes de financiamento e alavancar sua capacidade, de modo a tornarem-se sustentáveis e mais eficazes no alcance dos seus objetivos, pois ter múltiplos fluxos de receita poderia ser uma importante fonte de legitimidade para potencializar doações. Isto pode resultar de um desejo do setor empresarial de doar a instituições sem fins lucrativos estáveis, demonstrando alguma aversão ao risco na sua prática filantrópica (AL-TABBAA; LEACH; MARCH, 2014; SUÁREZ; HWANG, 2013).

As OSC, por sua vez, devem agir de uma forma socialmente responsável para com os seus doadores, fornecendo-Ihes informações financeiras precisas, por meio da adoção de ferramentas de gestão, proporcionando legitimidade a essa parceria e ajudando as OSC na diversificação de parceiros de colaboração, pois as empresas provavelmente querem doar para OSC que vão utilizar os seus recursos de forma eficiente e eficaz. Além disso, ir além do contexto de angariação de fundos ao convidar os doadores para eventos das OSC beneficiadas (PUYVELDE et al., 2012; SUÁREZ; HWANG, 2013).

As colaborações entre empresas e OSC, com comunicação, missão, confiança e compromisso, geram muitos benefícios potenciais para as OSC, além daqueles associados à mera disponibilização de dinheiro, como outros recursos e capacidades que ajudam os parceiros a melhorar a partilha de conhecimentos mais especializados, o que pode resultar em inovações sociais reais e mudança transformacional (SANZO et al., 2015).

Nesse cenário, as empresas que aceitam participar em ações de responsabilidade social contribuem significativamente para o bem-estar da sociedade, bem como na sua relação com as OSC para além de um tipo paternalista de sentido único, representada por doadores ricos e destinatários pobres, demonstrando uma boa conduta corporativa devido à preocupação social (CHO; KELLY, 2014).

\section{Metodologia}

A metodologia utilizada neste estudo tratou-se de uma pesquisa qualitativa, exploratória e sob o escopo de estudo de casos múltiplos. De acordo com Flick (2009), a pesquisa qualitativa é a mais indicada para entender e descrever as perspectivas dos participantes em suas práticas diárias, possibilitando experiências, interações e documentos em seu contexto natural.

Quanto ao objetivo, a pesquisa caracteriza-se como exploratória, pois tem a finalidade de, conforme Gil (2008), desenvolver, esclarecer e modificar conceitos e ideias, o que geralmente envolve levantamento bibliográfico e documental, entrevistas não padronizadas e estudos de caso, proporcionando uma visão geral sobre o fato a ser estudado.

A pesquisa qualitativa é a mais adequada para analisar as contribuições das práticas de RSE das empresas para com as OSC, tratando-se de uma pesquisa exploratória justamente porque buscou fazer uma análise dessas contribuições, o que pôde ser aprofundado por meio da abordagem de estudo de casos múltiplos (YIN, 2010).

A população da pesquisa incluiu todas as OSC, as quais somam um total de 270 registradas (OSC, 2015), e empresas que praticam RSE, indicadas pelas OSC da amostra da pesquisa, das quatro maiores cidades da região norte do Rio Grande do Sul (RS). Entretanto, não foi possível identificar a população total de empresas que praticam RSE no norte do RS.

A amostra da pesquisa foi selecionada por conveniência. Primeiramente foram identificadas as quatro maiores cidades da região norte do RS por meio de dados do IBGE (2014), de acordo com o número de habitantes (Passo Fundo, 195.620; Erechim, 101.752; Carazinho, 61.875; Marau, 39.693).Posteriormente, foram identificadas e selecionadas as OSC dessas cidades que participaram da pesquisa, a partir do website Mapa das organizações da sociedade civil (OSCS, 2015). Coerentemente, a amostra totalizou em 14 OSC selecionadas pelo website Mapa das Organizações da Sociedade Civil e 11 empresas selecionadas por indicação das OSC no momento das entrevistas. 
Para essa pesquisa foram utilizadas entrevistas semiestruturadas, individuais e em profundidade como instrumentos de coleta de dados. Os roteiros das entrevistas foram adaptados dos pressupostos teóricos das pesquisas de Aguilera et al. (2007); Amendola, Garofalo e Nese (2011); Jo e Harjoto (2011); Austin e Seitanidi (2012); Harris (2012);Agarwal (2014); Cho e Kelly (2014); Salamon (2010); e Sanzo et al. (2015).

Os dados primários foram coletados das próprias entrevistas, para as quais foram utilizados dois roteiros básicos de questões - um para as empresas e outro para as OSC.Já os dados secundários foram coletados dos documentos impressos disponibilizados por algumas empresas e OSC durante as entrevistas e também por meio de pesquisa nos websites das empresas e OSC.Ressalta-se ainda que os roteiros de perguntas, elaborados para as entrevistas, foram validados metodologicamente por dois experts na área temática de estudos antes de se aplicar às empresas e OSC.

Para a análise e interpretação dos dados, utilizou-se a técnica de análise de conteúdo (BARDIN, 2011), a partir de categorias de análise a priori, fundamentadas no referencial teórico e objetivos da pesquisa, sendo: i) contribuições das OSC; e, ii) contribuições da responsabilidade social empresarial para com as OSC. Esse tipo de análise trata-se de um conjunto de técnicas de análise das comunicações que utiliza procedimentos sistemáticos e objetivos de descrição do conteúdo das mensagens, em que podem ser analisados os significados (BARDIN, 2011).

Para manter o anonimato dos respondentes das OSC, utilizou-se os pseudônimos $\mathrm{O} 1, \mathrm{O} 2 \ldots \mathrm{O} 18$, e os nomes fictícios Alfa, Beta, Gama, Delta e Ômega para identificar as OSCs. Para identificar os entrevistados das empresas, foram utilizados os pseudônimos E1, E2 ... E13 Para manter a confidencialidade das empresas, utilizou-se os nomes fictícios Empresa A, Empresa B... Empresa K.

\section{Análise e discussão dos resultados}

As OSC participantes da pesquisa foram caracterizadas (Figura 1) e separadas conforme as ações que realizam para a sociedade (Figura 2), que ocorrem no período de 18/08/2015 a 24/09/2015. Com base nas entrevistas, material impresso ou digital disponibilizado pelas OSC e pelos próprios websites. Também com base nas entrevistas, material impresso disponibilizado pelas empresas ou pelos próprios websites, as empresas participantes foram caracterizadas (Figura 3 e 4), nas quais as entrevistas ocorrem de 27/08/2015 a $20 / 10 / 2018$.

Quadro 1 - Características das OSC participantes da pesquisa

\begin{tabular}{|c|c|c|c|c|c|c|}
\hline Cidade & OSC & $\begin{array}{c}\mathrm{N} \cdot{ }^{\circ} \text { de } \\
\text { colaboradores }\end{array}$ & $\begin{array}{c}\text { N. }{ }^{\circ} \text { de usuários/assistidos/ } \\
\text { beneficiados }\end{array}$ & Entrevistados & $\begin{array}{l}\text { Tempo de } \\
\text { atuação na } \\
\text { OSC }\end{array}$ & $\begin{array}{c}\text { Duração } \\
\text { da } \\
\text { entrev. }\end{array}$ \\
\hline \multirow{7}{*}{$\begin{array}{l}\text { Passo } \\
\text { Fundo }\end{array}$} & CEJUME & $\begin{array}{l}20 \text { entre fixos e } \\
\text { voluntários }\end{array}$ & $\begin{array}{c}75 \text { crianças e adolescentes } \\
74 \text { adultos }\end{array}$ & \begin{tabular}{|c|} 
(O1) Assistente \\
Social \\
(O2) Coordenadora \\
\end{tabular} & $\begin{array}{c}\text { (O1) } 2 \text { anos } \\
\text { (O2) } 24 \\
\text { anos }\end{array}$ & $58 \min$ \\
\hline & OSC Alfa & 95 colaboradores & $\begin{array}{c}468 \text { na educação infantil } \\
1053 \text { serviço de proteção básica } \\
1530 \text { nos cursos básicos } \\
\end{array}$ & (O3) Presidente & $\begin{array}{l}\text { (O3) } 1 \text { ano } \\
\text { e meio }\end{array}$ & $22 \min$ \\
\hline & $\begin{array}{l}\text { Lar Emiliano } \\
\text { Lopes }\end{array}$ & 10 colaboradores & 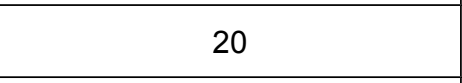 & $\begin{array}{l}\text { (O4) Assistente } \\
\text { Social }\end{array}$ & 15 anos & $26 \min$ \\
\hline & $\begin{array}{l}\text { Liga } \\
\text { Feminina } \\
\text { de Combate } \\
\text { ao Câncer e } \\
\text { CACC } \\
\end{array}$ & $\begin{array}{l}6 \text { colaboradores } \\
64 \text { voluntários }\end{array}$ & 29 & $\begin{array}{c}\text { (O5) Vice- } \\
\text { presidente } \\
\text { (O6) Assistente } \\
\text { Social e Pedagoga } \\
\text { (O7) Voluntária } \\
\end{array}$ & $\begin{array}{c}\text { (O5) } 1 \text { ano } \\
\text { e meio } \\
\text { (O6) } 4 \\
\text { meses } \\
\text { (O7) } 4 \text { anos }\end{array}$ & $44 \min$ \\
\hline & APAE-PF & $\begin{array}{l}65 \text { colaboradores } \\
10 \text { voluntários }\end{array}$ & 300 & (O8) Presidente & 4 anos & $37 \mathrm{~min}$ \\
\hline & $\begin{array}{l}\text { Fundação } \\
\text { Beneficente } \\
\text { Lucas Araújo } \\
\end{array}$ & 118 colaboradores & $\begin{array}{c}220 \text { na educação infantil } \\
146 \text { meninas no Lar da Menina } \\
70 \text { idosos } \\
\end{array}$ & (O9) Diretor Geral & $\begin{array}{l}2 \text { anos e } \\
\text { meio }\end{array}$ & $33 \min$ \\
\hline & SOCREBE & $\begin{array}{l}35 \text { colaboradores } \\
20 \text { estagiários } \\
6 \text { voluntários }\end{array}$ & $\begin{array}{c}432 \text { famílias no FACID } \\
300 \text { crianças e adolescentes no } \\
\text { PROCID } \\
230 \text { crianças na educação } \\
\text { infantil }\end{array}$ & $\begin{array}{c}\text { (O10) Assistente } \\
\text { Social }\end{array}$ & 6 anos & $21 \min$ \\
\hline
\end{tabular}


Continuação

\begin{tabular}{|c|c|c|c|c|c|c|}
\hline \multirow[t]{3}{*}{ Erechim } & $\begin{array}{l}\text { Sociedade } \\
\text { Fraternal } \\
\text { Cantinho da } \\
\text { Luz }\end{array}$ & $\begin{array}{l}25 \text { colaboradores } \\
38 \text { voluntários }\end{array}$ & $\begin{array}{c}144 \text { famílias (cerca de } \\
900 \text { pessoas atendidas } \\
\text { indiretamente) } \\
89 \text { crianças no serviço de } \\
\text { proteção básica } \\
40 \text { mães nas oficinas de } \\
\text { formação }\end{array}$ & (011) Presidente & 21 anos & $28 \mathrm{~min}$ \\
\hline & AAIE & 76 voluntários & $\begin{array}{c}1600 \text { (31 grupos de } \\
\text { convivência) }\end{array}$ & (012) Presidente & 7 anos & $57 \mathrm{~min}$ \\
\hline & $\begin{array}{l}\text { APAE - } \\
\text { Erechim }\end{array}$ & 66 colaboradores & 270 & (013) Presidente & 3 anos & $27 \mathrm{~min}$ \\
\hline \multirow[t]{2}{*}{ Carazinho } & $\begin{array}{l}\text { APAE - } \\
\text { Carazinho }\end{array}$ & 33 colaboradores & 240 & $\begin{array}{l}\text { (O14) Diretora } \\
\text { (O15) Presidente }\end{array}$ & $\begin{array}{c}(\mathrm{O} 15) 25 \\
\text { anos } \\
(\mathrm{O} 16) 1 \text { ano }\end{array}$ & $29 \mathrm{~min}$ \\
\hline & $\begin{array}{l}\text { Programa } \\
\text { Yacamim }\end{array}$ & 8 colaboradores & $\begin{array}{c}83 \text { na Sede } \\
100 \text { na Ação Rua }\end{array}$ & $\begin{array}{c}(\mathrm{O} 16) \\
\text { Coordenadora }\end{array}$ & 7 anos & $29 \mathrm{~min}$ \\
\hline \multirow[b]{2}{*}{ Marau } & $\begin{array}{l}\text { APAE - } \\
\text { Marau } \\
\end{array}$ & 37 colaboradores & 185 & (017) Presidente & 28 anos & $43 \min$ \\
\hline & $\begin{array}{l}\text { Fundação } \\
\text { Assistencial } \\
\text { e Cultural } \\
\text { José Fuga }\end{array}$ & $\begin{array}{c}1 \text { efetivo } \\
6 \text { terceirizados }\end{array}$ & 93 & $\begin{array}{c}(\mathrm{O} 18) \\
\text { Coordenadora }\end{array}$ & 10 anos & $25 \mathrm{~min}$ \\
\hline
\end{tabular}

Fonte: Dados da pesquisa.

Quadro 2 - Ações das OSC

\begin{tabular}{|c|c|c|}
\hline Cidade & OSC & Ações \\
\hline \multirow{7}{*}{$\begin{array}{l}\text { Passo } \\
\text { Fundo }\end{array}$} & CEJUME & $\begin{array}{l}\text { Marcenaria; Atendimentos social e psicológico; Capoeira; Dança; Música; Teatro; } \\
\text { Percussão; Projetos de extensão (psicologia e nutrição); Pintura; Crochê; Culinária } \\
\text { Manicure; Estética }\end{array}$ \\
\hline & OSC Alfa & $\begin{array}{l}\text { Educação Infantil; Dança; Esporte; Música; Inclusão digital; Cidadania; Artesanato; } \\
\text { Meio ambiente; Grupo de jovens; Cursos de educação sócio profissional; Atendimento } \\
\text { social, psicológico e odontológico }\end{array}$ \\
\hline & Lar Emiliano Lopes & Acolhimento institucional; Orquestra; Grupos de trabalho \\
\hline & $\begin{array}{l}\text { Liga Feminina de } \\
\text { Combate ao Câncer } \\
\text { e CACC }\end{array}$ & $\begin{array}{l}\text { Medicação; Acompanhamento psicossocial; Atendimento jurídico; Alimentação; } \\
\text { Hospedagem }\end{array}$ \\
\hline & OSC Beta & $\begin{array}{l}\text { Educação Infantil e Ensino Fundamental; Educação de Jovens e Adultos; Dança; } \\
\text { Teatro; Capoeira; Música; Coral; Produções variadas na linha artística; Esportes } \\
\text { Projeto de Compostagem Doméstica; Inserção no mercado de trabalho; Atendimento } \\
\text { odontológico e psicológico }\end{array}$ \\
\hline & $\begin{array}{l}\text { Fundação } \\
\text { Beneficente Lucas } \\
\text { Araújo }\end{array}$ & $\begin{array}{l}\text { Culinária; Música; Capoeira; Artesanato; Dança; Informática } \\
\text { Educação Infantil; Higiene; Alimentação; Espiritualidade } \\
\text { Atendimento médico e psicológico; Artesanato }\end{array}$ \\
\hline & OSC Gama & $\begin{array}{l}\text { Educação Infantil; Leitura; Desenho; Jogos; Dança; Gincanas; Práticas artesanais } \\
\text { e domésticas; Apoio familiar; Visitas domiciliares às famílias }\end{array}$ \\
\hline \multirow{3}{*}{ Erechim } & $\begin{array}{l}\text { Sociedade Fraternal } \\
\text { Cantinho da Luz }\end{array}$ & $\begin{array}{l}\text { Fortalecimento de vínculos familiares; Orientação sócio familiar; Ações culturais, } \\
\text { esportivas e sócio educativas; Esporte; Música; Xadrez; Sexualidade; Informática; } \\
\text { Psicomotricidade; Leitura; Cursos de padaria, horta e jardinagem Manutenção da } \\
\text { casa; Costura; Patchwork }\end{array}$ \\
\hline & AAIE & $\begin{array}{l}\text { Carnaval da } 3^{a} \text { Idade; Festa Junina; Eleição da Vovó do Ano; Matinés; Miss } \\
\text { Erechim; Oficinas ocupacionais; Grupos de dança; Atendimento nas áreas de } \\
\text { nutrição, geriatria, psicologia, odontologia, fisioterapia; Orientações jurídicas e } \\
\text { sociais; Projeto Idoso Multiplicador }\end{array}$ \\
\hline & OSC Delta & $\begin{array}{l}\text { Inserção no mercado de trabalho; Grupo de convivência; Lazer; Olimpíadas; } \\
\text { Melhoria da condição de vida do assistido; Alfabetização; Terapia ocupacional; } \\
\text { Oficinas de trabalhos manuais; Atendimento e visitas às famílias dos usuários; } \\
\text { Costura; Bordado }\end{array}$ \\
\hline
\end{tabular}


Continuação

\begin{tabular}{|l|l|l|}
\hline \multirow{5}{*}{ Carazinho } & OSC Ômega & $\begin{array}{l}\text { Ensino Fundamental; Educação de Jovens e Adultos; Artesanato; Panificação; } \\
\text { Confecção de tela; Lavanderia; Inclusão no mercado de trabalho; Grupo de } \\
\text { jovens; Inclusão na rede regular de ensino }\end{array}$ \\
\cline { 2 - 3 } & Programa Yacamim & $\begin{array}{l}\text { Artes; Música; Esportes; Reforço escolar; Grupo terapêutico; Informática; } \\
\text { Dança; Ação Rua; Atendimento psicológico; Atendimento médico e odontológico; } \\
\text { Profissionalização }\end{array}$ \\
\hline \multirow{3}{*}{ Marau } & $\begin{array}{l}\text { Oficinas de artes; Estimulação precoce; Fisioterapia; Fonoaudiologia; Neurologia; } \\
\text { Psicologia; Pedagogia; Pediatria; Serviço social } \\
\text { Terapia ocupacional; Sala snoezelen; Equoterapia; Mostras de trabalhos dos } \\
\text { alunos; } \\
\text { Oficinas de trabalhos manuais para as mães }\end{array}$ \\
\cline { 2 - 3 } & $\begin{array}{l}\text { Fundação } \\
\text { Assistencial e } \\
\text { Cultural José Fuga }\end{array}$ & Inglês; Ginástica artística; Coral infantil; Informática; Futsal \\
\hline
\end{tabular}

Fonte: Dados da pesquisa.

Quadro 3 - Características das empresas participantes da pesquisa

\begin{tabular}{|c|c|c|c|c|c|c|c|}
\hline Cidade & Empresa & $\begin{array}{l}\mathrm{N} .^{\circ} \text { de } \\
\text { colaboradores }\end{array}$ & $\begin{array}{l}\text { Tempo de } \\
\text { atuação no } \\
\text { mercado } \\
\text { brasileiro }\end{array}$ & \begin{tabular}{|l} 
Publica \\
Balanço \\
Social ou \\
relatório de \\
atividades?
\end{tabular} & Entrevistados & $\begin{array}{l}\text { Tempo de } \\
\text { atuação } \\
\text { na } \\
\text { empresa }\end{array}$ & $\begin{array}{l}\text { Duração } \\
\text { da } \\
\text { entrevista }\end{array}$ \\
\hline \multirow{5}{*}{$\begin{array}{l}\text { Passo } \\
\text { Fundo }\end{array}$} & Empresa A & 260 na unidade & 10 anos & Não & $\begin{array}{l}\text { (E1) Assessora de } \\
\text { Comunicação }\end{array}$ & 6 anos & $25 \min$ \\
\hline & Empresa B & 70 na unidade & 36 anos & Sim & $\begin{array}{l}\text { (E2) Gerente de } \\
\text { restaurante }\end{array}$ & 6 anos & $28 \min$ \\
\hline & Empresa C & $\begin{array}{l}7000 \mathrm{em} \text { todas as } \\
\text { unidades }\end{array}$ & 36 anos & Não & $\begin{array}{l}\text { (E3) Gestora } \\
\text { de marketing e } \\
\text { comunicação }\end{array}$ & 4 meses & $17 \mathrm{~min}$ \\
\hline & Empresa D & 150 na unidade & 30 anos & Não & $\begin{array}{l}\text { (E4) Supervisora de } \\
\mathrm{RH}\end{array}$ & 9 anos & $24 \min$ \\
\hline & Empresa E & $\begin{array}{l}180 \text { em todas as } \\
\text { unidades }\end{array}$ & 15 anos & Não & $\begin{array}{l}\text { (E5) Procurador e } \\
\text { Diretor Administrativo }\end{array}$ & 11 anos & $30 \mathrm{~min}$ \\
\hline \multirow[b]{2}{*}{ Erechim } & Empresa F & 400 & 41 anos & Não & $\begin{array}{l}\text { (E6) Responsável pelo } \\
\text { RH }\end{array}$ & 7 anos & $17 \min$ \\
\hline & Empresa G & 600 & 51 anos & $\begin{array}{l}\text { Só para a } \\
\text { Assembleia } \\
\text { Legislativa }\end{array}$ & $\begin{array}{l}\text { (E7) Analista Contábil } \\
\text { (E8) Analista Contábil } \\
\text { (E9) Responsável } \\
\text { Qualidade }\end{array}$ & \begin{tabular}{|l}
$(E 7) 17$ \\
anos \\
$(E 8) 17$ \\
anos \\
$(E 9) 7$ \\
meses \\
\end{tabular} & $35 \mathrm{~min}$ \\
\hline \multirow[b]{2}{*}{ Carazinho } & Empresa $\mathrm{H}$ & $\begin{array}{l}70 \text { em todas as } \\
\text { unidades }\end{array}$ & 52 anos & Não & (E10) Analista de RH & 2 anos & $30 \min$ \\
\hline & Empresa I & $\begin{array}{l}1300 \mathrm{em} \text { todas as } \\
\text { unidades }\end{array}$ & 50 anos & Sim & $\begin{array}{l}\text { (E11) Analista de } \\
\text { Desenvolvimento de } \\
\text { Pessoas }\end{array}$ & 3 anos & $23 \mathrm{~min}$ \\
\hline \multirow[t]{2}{*}{ Marau } & Empresa J & 3600 na unidade & 87 anos & Sim & $\begin{array}{l}\text { (E12) Coordenadora } \\
\text { do Comitê de } \\
\text { Investimento Local }\end{array}$ & 2 anos & $39 \mathrm{~min}$ \\
\hline & Empresa K & 365 & 68 anos & Não & (E13) Supervisor RH & 10 anos & $18 \mathrm{~min}$ \\
\hline
\end{tabular}

Fonte: Dados da pesquisa (2015). 
Quadro 4 - Ações de responsabilidade social das empresas

\begin{tabular}{|c|c|c|}
\hline Cidade & Empresa & Ações \\
\hline \multirow{5}{*}{ Passo Fundo } & Empresa A & $\begin{array}{l}\text { Auxílio financeiro a organizações sociais; Incentivo à cultura (Lei Rouanet); Disposição } \\
\text { de fundo social do imposto de renda; Voluntariado dos colaboradores; Campanhas de } \\
\text { arrecadação com os colaboradores. }\end{array}$ \\
\hline & Empresa B & $\begin{array}{l}\text { Instituto Empresa B; Reaproveitamento de material/separação de lixo; Arrecadação } \\
\text { para organizações sociais; Doação de moedas pelos clientes. }\end{array}$ \\
\hline & Empresa C & $\begin{array}{l}\text { Compra ou aluguel de prédios históricos para a preservação do patrimônio histórico e } \\
\text { arquitetônico; Doação de produtos e alimentos para organizações sociais; Campanhas } \\
\text { de arrecadação entre os colaboradores. }\end{array}$ \\
\hline & Empresa D & $\begin{array}{l}\text { Campanhas do agasalho; Doação de fraldas para creches; Alimentação ou dinheiro } \\
\text { para realização de eventos beneficentes; Campanhas de arrecadação para ajudar } \\
\text { colaboradores; Doação em dinheiro e de alimento para organizações sociais. }\end{array}$ \\
\hline & Empresa E & Doações em dinheiro para algumas organizações sociais; Campanhas diversas. \\
\hline \multirow[t]{2}{*}{ Erechim } & Empresa F & $\begin{array}{l}\text { Coleta seletiva de lixo; Tratamento de efluentes; Uso de materiais recicláveis e madeira } \\
\text { de procedência legal; Campanhas internas sobre qualidade de vida e saúde dos } \\
\text { colaboradores; Campanhas sobre consumo de água e cuidados como meio ambiente; } \\
\text { Ginástica laboral; Incentivo à educação e ao esporte; Ajuda financeira a algumas } \\
\text { organizações sociais; Campanhas de doação envolvendo os colaboradores. }\end{array}$ \\
\hline & Empresa G & $\begin{array}{l}\text { Reciclagem de resíduos; Consciência ambiental; Segurança para os trabalhadores; } \\
\text { Arrecadação de roupas, alimentos e brinquedos entre os colaboradores; Destinação } \\
\text { do imposto de renda para o incentivo à cultura; Doação mensal em dinheiro para uma } \\
\text { entidade. }\end{array}$ \\
\hline \multirow[b]{2}{*}{ Carazinho } & Empresa $\mathrm{H}$ & $\begin{array}{l}\text { Instituto Empresa H; Campanhas do agasalho e de arrecadação de brinquedos; Doação } \\
\text { em dinheiro para algumas organizações sociais; Visitas à uma organização social; } \\
\text { Campanhas de arrecadação para ajudar colaboradores em situações graves; Trabalho } \\
\text { anual sobre o meio ambiente com crianças de escolas. }\end{array}$ \\
\hline & Empresa I & $\begin{array}{l}\text { Coleta de água da chuva; Utilização de linhas pressurizadas no combate a incêndios; } \\
\text { Palestras e campanhas de conscientização sobre o meio ambiente; Áreas de preservação } \\
\text { ambiental; Utilização de xícaras em vez de copos descartáveis; Destinação correta de } \\
\text { resíduos químicos e materiais como pilhas, pneus, madeiras quebradas; Campanhas } \\
\text { para a doação de brinquedo, agasalho, material escolar; Campanhas de educação no } \\
\text { trânsito; Parceria com o programa Na Mão Certa contra a exploração sexual de crianças } \\
\text { e adolescentes nas estradas; Visitas ao asilo e às escolas para entregar doações ou } \\
\text { conversar com os usuários; Contribuição financeira mensal para uma organização } \\
\text { social; Voluntariado dos colaboradores. }\end{array}$ \\
\hline \multirow[t]{2}{*}{ Marau } & Empresa J & $\begin{array}{l}\text { Instituto Empresa J; Programa de voluntários; Programa Portas Abertas; Programa de } \\
\text { Saúde, Segurança e Meio Ambiente (SSMA) dentro e fora da empresa; Campanhas } \\
\text { ambientais; Doações de produtos para creches, escolas e organizações sociais; Doações } \\
\text { para eventos beneficentes. }\end{array}$ \\
\hline & Empresa K & $\begin{array}{l}\text { Fundação Assistencial e Cultural; Preservação do meio ambiente; Contra o trabalho } \\
\text { infantil e trabalho forçado; Doação de retalhos de couro para uma organização social; } \\
\text { Eventuais brincadeiras e gincanas com os alunos de uma organização social. }\end{array}$ \\
\hline
\end{tabular}

Fonte: Dados da pesquisa.

Neste contexto, a figura 4 apresenta as principais ações de RSE desenvolvidas pelas empresas pesquisadas, dentre as quais estão o auxílio financeiro para organizações sociais, doação de produtos e alimentos, campanhas de doação envolvendo os colaboradores, palestras e campanhas de conscientização sobre o meio ambiente, entre outras.

\subsection{Contribuições das OSC}

Algumas contribuições das OSC que participaram da pesquisa para os beneficiados em si referemse à inclusão na sociedade, à defesa dos seus direitos, à convivência e troca de experiências com outras pessoas, à autonomia, à qualidade de vida, à formação e profissionalização das pessoas, ao acolhimento, à orientação, à socialização, à proteção, à valorização, à auto estima, à hospedagem, à alimentação, à saúde e ao vestuário, entre outros. 
Essas contribuições demonstram que as OSC pesquisadas estão tentando gerenciar as questões sociais em prol da valorização do ser humano, da sociedade e do meio ambiente, disseminando comportamentos baseados em altruísmo e solidariedade, e promovendo o bemestar social (AMENDOLA; GAROFALO; NESE, 2011), conforme se percebe na fala dos entrevistados:

(...) a gente tenta buscar a inclusão deles na sociedade né, e fazer de uma forma geral a defesa dos direitos (...) tenta colocar eles nos espaços em que todo mundo está circulando, porque eles têm esse direito, enquanto indivíduos (...) sempre esse intuito de eles estarem convivendo com os outros (...) (O8).

(...) fazemos elas entenderem porque elas estão nesta situação, então a gente possibilita que as pessoas desenvolvam esse potencial, acreditando que podem mudar o padrão de vida, a partir daí a gente faz o trabalho de formação (...) (O11).

A respeito das contribuições das ações das OSC para a sociedade e no desenvolvimento regional, pode-se dizer que envolve a diminuição de custos para o Estado, a aprendizagem a conviver com a diferença, a formação de cidadãos melhores e mais conscientes, o apoio às empresas no cumprimento da legislação de inclusão social de deficientes no mercado de trabalho, e a criação ou melhoria dos vínculos familiares e, até mesmo, contribuições ambientais.

Nesse contexto, devido à limitação do governo em atender às demandas sociais, surgem as OSC para preencher essa lacuna por meio de suas ações, pois são capazes de canalizar a participação popular, buscando identificar causas e propor soluções para os problemas sociais, de modo que são consideradas essenciais para ajudar a entregar serviços humanos vitais, como saúde, educação, aconselhamento, entre outros (SALAMON, 1998; SALAMON, 2010), corroborando com o ponto de vista dos entrevistados:

(...) qualquer atividade social que você faça voluntariamente, você está diminuindo o custo para o Estado (...) é um ganho pra uma sociedade que eu acho que atualmente é bem egocentrista né, então você conseguir conviver com a diferença já é uma boa caminhada (...) (O8).

(...) você conseguir fazer uma pessoa assim avançar na questão pedagógica e depois conseguir também arrumar um trabalho, (...) se aposentar dignamente (...) é uma grande contribuição que você está fazendo para a sociedade (...) todas as ações são para melhorar o cidadão (...) (O17).

Esse pensamento é compartilhado também pelas empresas, conforme apontado pelos entrevistados:

(...) é uma opção da empresa fazer isso (...) a gente acaba, pela forma como a empresa age e faz algumas entregas para a comunidade, suprindo lacunas que o Estado deixa em aberto (...) (E3).

(...) eu acredito muito que as empresas cada vez mais (...) por questões de falta de governo, elas têm que ter cada vez mais essa responsabilidade social (...) (E5).

Assim sendo, muitas vezes as OSC buscam cumprir sua missão por meio de parcerias com o Estado e as empresas,Elas têm, principalmente, a capacidade de envolver a iniciativa privada em apoio a fins públicos, o que está de acordo como as pesquisas de Salamon (2010) e Amendola, Garofalo e Nese (2011).

\subsection{Contribuições da responsabilidade social empresarial para as OSC}

As empresas podem contribuir com as OSC e com a sociedade de diversas maneiras, não apenas com doações em dinheiro ou com a geração de empregos. Também por meio de acompanhamento dos trabalhos desenvolvidos pelas OSC, ou por meio de trabalhos voluntários, como forma de demonstrar sua preocupação e apoiar os usuários, buscando dar um retorno maior para a comunidade onde as empresas estão inseridas,oque é corroborado por Carroll e Shabana (2010), Harris (2012), Austin e Seitanidi (2012), Agarwal (2014), Cho e Kelly (2014) e Sanzo et al. (2015). Essas autores ressaltam a importância das ações de RSE não apenas em sentido financeiro ou material, mas envolvendo-se diretamente no trabalho das OSC, compartilhando conhecimentos, capacidades, práticas de gestão e habilidades, indo além de uma relação paternalista de sentido único, mas como uma contrapartida, em que cada parceiro fornece insumos, 
de forma que a empresa pode dar fundos e a OSC pode oferecer um serviço social. Isso pode ser verificado também nas falas dos entrevistados:

(...) é também importante que a gente visite eles, que outras pessoas enxerguem eles (...) não só o contribuir financeiramente (...) a gente não está aqui só para produzir, dar emprego ou estar, a gente tem que ter esse retorno, assim como a comunidade nos auxiliou, quando a gente quis se instalar aqui (...) (E1).

(...) dar uma contrapartida, entregar alguma coisa, que as pessoas percebam que a gente não está lá só para botar loja (...) e a gente sabe que isso vai bem além da doação (...) (E3).

(...) eu acho que é uma contrapartida né, nós entramos com o serviço prestado para a comunidade e eles com o valor que eles têm que destinar a alguma instituição (...) (O14).

(...) algumas entidades a gente ajuda somente com dinheiro, mas na minha opinião a gente tem que ter um outro envolvimento, que é a atenção, o carinho, essa outra parte mais social mesmo assim de poder ajudar mesmo as pessoas (...) (E10).

Nesse cenário, as OSC, por não terem recursos próprios, em sua maioria, passam por dificuldades e limitações no que se refere à busca de recursos e, concomitantemente, falta de tempo para trabalhar nas ações propriamente ditas, ou ainda os recursos recebidos por meio de projetos ou convênios públicos que são destinados para um fim previamente determinado, mas acabam limitando sua disponibilidade de caixa para despesas que surgem, como a manutenção de seus espaços, de maneira que a contribuição das empresas com esses recursos pode ajudar as OSC dessa forma.

Da mesma forma, Verschuere e De Corte (2014), ressaltam que a dependência de recursos já direcionados para um determinado fim parece ter um impacto negativo sobre os procedimentos de trabalho e, consequentemente, sobre os resultados a serem alcançados. O que é uma preocupação das OSC e também das empresas que participaram da pesquisa, sendo destacado pelos entrevistados:

(...) recursos quando vêm, por exemplo, do fundo municipal da criança e do adolescente, é ótimo que veio, só que normalmente já vem com uma rubrica dizendo assim vocês têm que aplicar em obra de fazer tal coisa, adquirir tal coisa, mas para a manutenção da casa, para outras coisas que eles precisam eles não têm essa verba circulante (...) (E1).

(...) normalmente a entidade funciona a partir de convênios ou projetos né, logo o convênio ele fica engessado, (...) e os projetos de igual forma, então esse recurso ele (...) serve para um gerenciamento das outras coisas, da manutenção, de um transporte, de uma medicação que não está prevista, de um passeio, de um lazer, de um lanche extra, ou seja, para a gente poder dar o desfecho do cotidiano mesmo né, que às vezes são ações que não estão previstas no projeto e não estão atreladas a um convênio (...) (O4).

Para algumas empresas (por exemplo, empresas $A, D, E, G, H, K$ ) a ajuda às organizações sociais já está programada nos seus orçamentos, mas outras podem ter dificuldades na contabilização das doações, o que pode levá-las a buscar outros meios de ajudar a comunidade, de acordo com o que dizem os entrevistados:

(...) isso entra nos nossos orçamentos do que a gente vai fazer para os próximos anos (...) a gente sempre faz a manutenção desses valores (...) (E1).

(...) às vezes acontece assim né, que a empresa, como tem essa dificuldade de caixa né, às vezes o proprietário, ele tira do bolso dele né, e não entra através da empresa, por causa da dificuldade de contabilizar essa despesa (...) a Empresa A eu sei que eles nos ajudam e isso vai para a despesa, é considerado despesa mesmo (...) e as empresas não querem fazer assim porque daí fica ruim depois para o balanço deles (...) (O8).

Nesse contexto, de acordo com Minzner et al. (2014), algumas empresas podem investir nas OSC por meio de assistência, treinamento e fundos de subsídios técnicos para melhorar a função dessas organizações e os resultados para os beneficiados, suprindo falhas de gestão que as OSC possam a ter,como é mostrado na fala de um entrevistado:

(...) nós tivemos também uma empresa que (...)direcionou um recurso para nós, mas já destinado para nós capacitarmos a gestão (...) decidimos então implantar o planejamento estratégico (...) se a gente não tiver gestão, se a gente não tiver um olhar bem atento, 
acho que muitas entidades vão sofrer muito, não sei algumas se vão conseguir sobreviver, então a gente está fazendo isso com muito cuidado (...) a capacitação da gestão e capacitação profissional são coisas que eu prezo muito (...) (017).

Por fim, sobre a importância das contribuições das empresas para com as OSC, destaca-se que são uma forma de as empresas ajudarem as comunidades onde estão inseridas e de as OSC poderem contar com um recurso a mais que, por menor que seja,independentemente do tipo de doação, pode ser um complemento para que as OSC prestem seus serviços da melhor forma possível.

De acordo com Aguilera et al. (2007), as necessidades das OSC por colaborações podem ser um incentivo para a participação das empresas em atividades de responsabilidade social. Essas colaborações podem resultar na melhoria dos serviços das OSC e em mudanças sociais mais amplas (SUARÉZ; HWANG, 2013; SANZO et al., 2015), como percebe-se na fala dos entrevistados:

(...) contribui para que nós possamos dar aquela respirada, no sentido de poder gestar, de poder proporcionar inclusive um melhor atendimento (...) seja com recurso, seja com o voluntariado (...) eu acho que o que vem da responsabilidade social é proporcionar os acolhidos nossos, o algo mais, seja no lazer, seja na alimentação, no vestuário, no estudo (...) (O4).

(...) tira nossas crianças da rua, e essas crianças veem uma oportunidade, uma possibilidade de educação melhor (...) (E7).

Assim, vimos que, apesar de as OSC receberem, algumas vezes, recursos de outros setores, não são suficientes para manter seus serviços, sendo a ajuda que vem das empresas ou da comunidade no geral importante para amenizar essa deficiência,pois,muitas vezes, possibilitam que as OSC ofereçam aos usuários benefícios além dos que constam em sua missão. Dessa forma, destacam-se na figura 4 as contribuições da RSE para as OSC que participaram da presente pesquisa.

\section{Conclusão}

Entre algumas das dificuldades percebidas pelas OSC está o fato de que a maior parte dos recursos recebidos tendem a limitar sua gestão, pois sua finalidade já é previamente definida, não podendo ser utilizados de outra forma, o que pode dificultar a manutenção dos seus espaços, bem como limitar ações para proporcionar aos usuários um conforto maior.

As contribuições das ações das OSC para a sociedade são relevantes, pois, como mencionado pelos próprios entrevistados, o terceiro setor está desempenhando funções que o setor público está limitado a desempenhar, de acordo com Salamon $(1998,2010)$. Destaca-se que elas primam pela formação das pessoas, buscando inserir na sociedade pessoas melhores e mais conscientes, e possibilitar que indivíduos em vulnerabilidade social, ou situações de risco, tenham oportunidade de buscar por mudanças de vida.

Ressalta-se que as empresas e as OSC da presente pesquisa compartilham a ideia de que as contribuições não precisam ser necessariamente apenas em dinheiro, havendo outras formas de contribuir, por exemplo, com voluntariado dos colaboradores, compartilhamento de conhecimentos e práticas de gestão, o que está de acordo com os pressupostos de Carroll e Shabana (2010), Harris (2012), Austin e Seitanidi (2012), Agarwal (2014), Cho e Kelly (2014) e Sanzo et al. (2015).

As OSC concordam que os recursos e a ajuda fornecidos pelas empresas, por serem mais flexíveis, que não necessitam ser aplicados a um fim predeterminado, são muito relevantes para despesas não previstas ou para fazer algo a mais pelos beneficiados. Coerentemente, ambas concordam também que as contribuições das empresas com as OSC são uma contrapartida, uma via de mão dupla, o que está de acordo com Austin e Seitanidi (2012), que destacam que cada parceiro fornece insumos, sendo que a empresa pode dar fundos e a OSC pode oferecer um serviço social.

Em suma, os principais achados da presente pesquisa referem-se à confirmação de que terceiro setor e as empresas desempenham atividades que seriam do Estado, o que contribui significativamente com o desenvolvimento regional do norte do RS.As OSC primam pela formação das pessoas, para inserir 
na sociedade pessoas mais conscientes, educadas e que saibam valorizar o convívio social e o trabalho em equipe, possibilitando que tenham oportunidades de buscar por mudanças de vida.

Coerentemente, as OSC buscam a inclusão de pessoas na sociedade, a defesa dos seus direitos, a convivência e troca de experiências com outras pessoas, a autonomia, a qualidade de vida, a formação e profissionalização das pessoas, assim como o acolhimento, a orientação, a socialização, a proteção, a valorização, a autoestima, a hospedagem, a alimentação e a saúde, entre outros.

Além disso, as OSC diminuem os custos para o Estado, ensinam a conviver com a diferença, formam cidadãos mais conscientes, apóiam as empresas no cumprimento à legislação de inclusão social de deficientes no mercado de trabalho, criam ou melhoram os vínculos familiares e, até mesmo,fazem contribuições ambientais.

Finalmente, ressalta-se que os recursos e outras ajudas oferecidos pelas empresas às OSC são significativos, principalmente, para despesas não previstas que surgem na rotina das OSC, bem como para melhorar o atendimento aos beneficiados, visto que as contribuições entre empresas e OSC são vistas como uma contrapartida, onde as empresas fornecem insumos e as OSC oferecem serviços sociais.

Dentre as limitações encontradas no campo da pesquisa, destaca-se, principalmente, a dificuldade no acesso às empresas e a escassez de informações fornecidas por alguns entrevistados, talvez por seu pouco tempo de atuação na empresa. Outra limitação importante é a abrangência da pesquisa, pois foi aplicada em uma região específica, de modo que os resultados referem-se à amostra dessa região, não podendo ser generalizados, pois cada região tem suas particularidades.

Sugere-se, para estudos futuros, que a pesquisa seja replicada em outras regiões do estado, ou do país, bem como aplicada em outros tipos de OSC. Outra sugestão é a realização de pesquisas que tangenciem as parcerias entre as próprias OSC, assim como dessas com o setor público. Ainda sugere-se,como forma de ampliar a pesquisa, que seria interessante incluir alguns beneficiados, para entender como eles visualizam o trabalho das OSC e as contribuições das empresas, bem como as parcerias formadas por ambas.

\section{Referências}

AGARWAL, A. The new spectrum of corporate social responsibility in emerging economies. International Journal of Engineering and Management Research, [S.I], v. 4, n. 1, p. 32-36, 2014.

AGUILERA, R. V. et al. Putting the s back in corporate social responsibility: a multilevel theory of social change in organizations. Academy of Management Review, [S.I], v. 32, n. 3, p. 836-863, 2007.

AL-TABBAA, O.; LEACH, D.; MARCH. J. Collaboration between nonprofit and business sectors: a framework to guide strategy development for nonprofit organizations. Voluntas, [S.I], v. 25, n. 3, p. 657678,2014

AMENDOLA, A.; GAROFALO, M. R; NESE, A. Is the third sector an emerging economic institution? Social preferences versus poverty traps. Nonprofit and Voluntary Sector Quarterly, [S.I], v.40, n. 5, p. 850-872, 2011.

AUSTIN, J. E. Strategic collaboration between nonprofits and business. Nonprofit and Voluntary Sector Quarterly, [S.I], v. 29, n. 1, p. 69-97, 2000.

AUSTIN, J. E.; SEITANIDI, M. M. Collaborative value creation: a review of partnering between nonprofits and businesses part I: value creation spectrum and collaboration stages. Nonprofit and Voluntary

Sector Quarterly, [S.I], v. 41 n. 5, p. 726-758, 2012.

BARDIN, L. Análise de conteúdo. São Paulo: Edições 70, 2011.

BARTIK, T.; EBERTS, R.The roles oftax incentives andother business incentives in local economicdevelopment. In: Nancy BROOKS, N.; DONAGHY, K.; KNAAP, G.J.(Eds). The oxford handbook of urban economics and planning. New York, NY: Oxford University Press, 2012. p. 634654. 
BORGES, E. B. Incentivos fiscais e desenvolvimento socioeconômico de Goiás: análise de impactos dos Programas FOMENTAR e PRODUZIR (1995-2011). 2014, 287f. Tese (Doutorado do Programa de Pós-Graduação em Políticas Públicas, Estratégias e Desenvolvimento) - Instituto de Economia, Universidade Federal do Rio de Janeiro - UFRJ, Rio de Janeiro, 2014.

BOULOUTA, I.; PITELIS, C. N. Who needs CSR? The impact of corporate social responsibility on national competitiveness. Journal of Business Ethics, [S.I], v. 119, n. 3, p. 349-364, 2014.

CARROLL, A. B. The four faces of corporate citizenship. Business and Society Review, [S.I], v. 100, n. 101, p. 1-7, 1998.

CARROLL, A. B.; SHABANA, K. M.The business case for corporate social responsibility: a review of concepts, research and practice. International Journal of Management Reviews, [S.I], v. 12, n. 1, p. 85-105, 2010.

CHIN, M. K., HAMBRICK, D. C.; TREVIÑO, L. K. Political ideologies of CEOs: the influence of executives' values on corporate social responsibility. Administrative Science Quarterly, [S.I], v. 58, n. 2, p. 197-232, 2013.

CHO, M.; KELLY, K. S. Corporate donor-charitable organization partners: a coorientation study of relationship types. Nonprofitand Voluntary Sector Quarterly, [S.I], v. 43, n. 4, p. 693-715, 2014.

CORRIGAN, C. C. Corporate social responsibility and local context: The case of mining in Southern Africa. Resources Policy, [S.I],v. 55, p. 233-243, 2018.

CUADRA, F. M. de la. Os desafios da política social na América Latina. Cadernos de Gestão Pública e Cidadania, São Paulo, v. 19, n. 64, p. 78-92, jan./jun. 2014.

FLICK, U. Introdução à pesquisa qualitativa. Tradução Joice Elias Costa. 3. ed. Porto Alegre: Artmed, 2009.

GIL, A. C. Métodos e técnicas de pesquisa social. 6. ed. São Paulo: Atlas, 2008.

HARRIS, M. E. Nonprofits and business: toward a subfield of nonprofit studies. Nonprofit and Voluntary Sector Quarterly, [S.I], v. 41, n. 5, p. 892-902, 2012.

INSTITUTO BRASILEIRO DE GEOGRAFIA E ESTATSTICA (IBGE). Cidades. 2014. Disponível em: $<$ http://www.cidades.ibge.gov.br/xtras/uf.php?lang=\&coduf=43\&search=rio-grande-do-sul>. Acesso em: 31 maio 2015.

JO, H.; HARJOTO, M. A. Corporate governance and firm value: the impact of corporate social responsibility. Journal of Business Ethics, [S.I], v. 103, n. 3, p. 351-383, Oct. 2011.

LIN-HI, N.; HÖRISCH, J.; BLUMBERG, I. Does CSR matter for nonprofit organizations? Testing the link between CSR performance and trustworthiness in the nonprofit versus for-profit domain.Voluntas, [S.I], v. 26, n. 5, p. 1944-1974, Oct. 2015.

LENZIARDI, R. A gestão sustentável de pequenas empresas hoteleiras em Paraty (RJ): percepções e práticas. Revista Eletrônica Gestão \& Sociedade, [S.I], v. 11, n. 28, p. 558-1582, jan./abr.2017.

MACKEY, A.; MACKEY, T. B.; BARNEY, J. B. Corporate social responsibility and firm performance: investor preferences and corporate strategies. [S.I], Academy of Management Review, v. 32, n. 3, p. 817-835, Jul. 2007.

MATHIS, A. A.; MATHIS, A. Responsabilidade social corporativa e direitos humanos: discursos e realidades. Revista Katálysis, Florianópolis, v. 15, n. 1, p. 131-140, jan./jun. 2012.

MATTEN, D.; MOON, J. "Implicit" and "explicit" CSR: a conceptual framework for a comparative understanding of corporate social responsibility. Academy of Management Review, Briarcliff Manor, NY, v. 33, n. 2, p. 404-424, 2008.

MENDONÇA, J. R. C.; GONÇALVES, J. C. S.Responsabilidade social nas empresas: uma questão de 
imagem ou de essência? Organizações \& Sociedade, Salvador, v. 11, n. 29, p. 115-130, jan./abr. 2004.

MINZNER, A.; KLERMAN, J. A., MARKOVITZ, C. E.; FINK, B. The impact of capacity-building programs on nonprofits: a random assignment evaluation. Nonprofit and Voluntary Sector Quarterly, [S.I], v. 43, n. 3, p. 547-569, Jun. 2014.

MINISTÉRIO DO DESENVOLVIMENTO SOCIAL (MDS). 2017. Disponível em: <http://mds.gov.br/ assuntos/bolsa-familia>. Acesso em: 06 abr. 2018.

NOVAES, F. S. O Bolsa Família no contexto das políticas públicas.In: ENCONTRO DE ADMINISTRAÇÃO PÚBLICA E GOVERNANÇA - EnAPG, 2010, Vitória/ES. Anais...Vitória: ANPAD, 20107. p.1-17.

OHANA, M.; MEYER, M.; SWATON, S. Decision-making in social enterprises: exploring the link between employee participation and organizational commitment. NonprofitandVoluntary Sector Quarterly, [S.I], v. 42, n. 6, p. 1092-1110, Sep. 2012.

OMETTO, M. P. D. S. D. L; BULGACOV, S.; MAY, M. R. A efetividade dos estrategistas da responsabilidade social empresarial. Organizações \& Sociedade (O\&S), Salvado, v. 22, n. 74, p. 423442, jul./set.2015.

ORGANIZAÇÕES DA SOCIEDADE CIVIL (OSC). Mapa das Organizações da Sociedade Civil, 2015. Disponível em: <https://mapaosc.ipea.gov.br/>. Acesso em: 26 maio 2015.

PUYVELDE, S. V.; CAERS, R.; BOIS, C. D.; JEGERS, M. The governance of nonprofit organizations: integrating agency theory with stakeholder and stewardship theories. Nonprofit and Voluntary Sector Quarterly, [S.I], v. 41, n. 3, p. 431-451, May 2012.

REGO, A.; LEAL, S.; PINA E; CUNHA, M. How the perception of five dimensions of corporate citizenship and their inter-inconsistencies predict affective commitment. Journal of Business Ethics, [S.I], v. 94, n.1, p. 107-127, Jun. 2010.

RODRIGUES, M.; MENDES, L. Mapping of the literatureon social responsibility in the mining industry: a systematic literature review. JournalofCleanerProduction, [S.I], v. 181, p. 88-101, Apr. 2018.

SALAMON, L. M. A emergência do terceiro setor: uma revolução associativa global.Revista de Administração, São Paulo,v.33,n. 1, p. 5-11, jan./fev./mar. 1998.

.Putting the civil society sector on the economic map of the world. Annals of Public and Cooperative Economics, [S.I], v. 81, n. 2, p. 167-210, Jun. 2010.

SANZO, M. J.; ÁLVAREZ, L. I.; REY, M.; GARCÍA, N. Business-nonprofit partnerships: do their effects extend beyond the charitable donor-recipient model? Nonprofit and Voluntary Sector Quarterly, [S.I], v. 44, n. 2, p. 379-400, Jan. 2015.

SAUERBRONN, F. F.; SAUERBRONN, J. F. R. Estratégias de responsabilidade social e esfera pública. Revista de Administração Pública, Rio de Janeiro, v. 45, n. 2, p. 435-58, mar./abr, 2011.

SCHIE, S. V.; GÜNTERT, S. T.; OOSTLANDER, J.; WEHNER, T. How the organizational context impacts volunteers: a differentiated perspective on self-determined motivation. Voluntas, [S.I], v. 26, n. 4, p. 15701590, 2015.

SERAMIM, R. J.; ZANELLA, T. P.; ROJO, C. A. A Sustentabilidade e gestão da imagem: um estudo de caso em cooperativa agroindustrial do oeste do Paraná. Revista de Gestão Ambiental e Sustentabilidade,São Paulo,v. 6, n. 3, p. 15-33, set./dez. 2017.

SUÁREZ, D. F.; HWANG, H. Resource constraintsor cultural conformity? Nonpro fit Relation shipswith Businesses. Voluntas, [S.I], v. 24, n. 3, p. 581-605, Sep. 2013.

ORGANIZAÇÃO DAS NAÇÕES UNIDAS PARA A EDUCAÇÃO, A CIÊNCIA E A CULTURA (UNESCO). Políticas sociais para o desenvolvimento: superar a pobreza e promover a inclusão. Brasília: 
Ministério do Desenvolvimento Social e Combate à Fome, UNESCO, 2010. 360p.

VERSCHUERE, B.; DE CORTE, J. The impact of public resource dependence on the autonomy of NPOs in their strategic decision making. Nonprofit and Voluntary Sector Quarterly, [S.I], v. 43, n. 2, p. 293313, 2014.

WANG, H.; QIAN, C. Corporate philanthropy and corporate financial performance: the roles of stakeholder response and political access. Academy of Management Journal, [S.I], v. 54, n. 6, p. 11591181, Dec. 2011.

WANG, Z.; SARKIS, J. Corporate social responsibility governance, outcomes, and financial performance. Journal of Cleaner Production, [S.I], v. 162, p. 1607-1616, Sep. 2017.

WONG, E. M.; ORMISTON, M. E.; TETLOCK, P. E. The effects of top management team integrative complexity and decentralized decision making on corporate social performance. Academy of Management Journal, Briarcliff Manor, NY, v. 54, n. 6, p. 1207-1228, Dec. 2011.

YADLAPALLI, A.; RAHMAN, S.; GUNASEKARAN, A. Socially responsible governance mechanisms for manufacturing firms in apparel supply chains. International Journal of Production Economics, [S.I], v. 196, p. 135-149, Fev.2018.

YIN, R. K. Estudo de caso: planejamento e métodos. 4. ed. Porto Alegre: Bookman, 2010

Submetido em: 02/08/17

Aprovado em: 10/04/18 